\title{
Developing Personal Selling SOP, Improving Website and Improving Company Profile of MSME of PT. Selula Dwiphaloka Teknologi
}

\author{
Fabian Danandjaya Puspadewa ${ }^{1}$ and Hasnul Suhaimi ${ }^{1}$
}

\begin{abstract}
The increasing number of MSMEs (Micro, Small and Medium Enterprises) in Indonesia has had a positive contribution to Indonesia's economy, but many MSMEs unable to manage their business well. PT Selula Dwiphaloka Technologi is an MSME, a family business located in Bekasi City, Indonesia, that sells a custom-design machine for B2B customer. The data were collected using business coaching methods, a qualitative research that used to mapping MSME's condition and problem, then take a corrective action to implement solutions for improvement. The result shows that the MSME don't have a written SOP that can be used as guidance so the personal selling activity can be done consistenly, and also the website and company profile of MSME don't look very interesting. So, the solution is by developing SOP of personal selling, improving the website and company profile to support marketing activities. Surveys were also conducted to support evidence of the improvement result. As the results, there was a significant increase in the respondents' assessment of the visual aspects, information and overall appearance of the new website and company profile compared to the old ones. This study aims to help PT Selula Dwiphaloka Teknologi manage their marketing activities by creating SOP of personal selling, designing new website and company profile proposal.
\end{abstract}

Keywords-B2B, Business Coaching, Company Profile Design, Machine Maker MSMEs, Personal Selling SOP, Website Design.

\section{INTRODUCTION}

Based on data from the Central Bureau of Statistics, the number of MSMEs (Micro, Small and Medium Enterprises) in Indonesia rose to as much as 59.2 million in 2017 compared to 2013 , which amounted to 57.8 million of MSMEs. This considerable development makes MSMEs one of the largest contributors to GDP [1]. Of course, the increasing number of MSMEs makes the competition among MSMES has also increased. Every business must be able to maintain and develop its market both old and new consumers, so that profits can increase and these consumers do not move to competitors. But this is not easy. It takes a marketing strategy and a good marketing tool in order to gain new customers and to retain old customers. There are also many MSME owners who do not have good

\footnotetext{
${ }^{1}$ Fabian Danandjaya Puspadewa and Hasnul Suhaimi Departement of Economic and Business, Universitas Indonesia, Depok, Indonesia. E-mail: iandanand@gmail.com; hasnuls@gmail.com.
}

marketing competencies and work alone, so they have difficulty running their business. However, MSME owners still have to do marketing that is suitable for their business growth even though they do not have the resources or operational structures that support such a large company [2].

PT Selula Dwiphaloka Technologi is a MSME that provide engineering services solution. These MSMEs provide solutions to target consumers such as a custom design machine, fabrication, maintenance, and repairment. The MSME has expertise in automation, mechanical, and electrical. The services provided are all custom services that the customer need. These MSMEs have adequate equipment and workplaces. Moreover, it is located in the city of Bekasi, which is close to the target consumers who are industry players in the Jakarta area to Cikarang.

The main target consumers of PT Selula Dwiphaloka Technologi are B2B consumers (business to business). The industry chosen is mainly a small to large scale private industry engaged in manufacturing. Because the services provided are quite diverse, the potential of consumers of PT Selula Dwiphaloka Technologi will continue to exist as long as there is a need for maintenance, repairment and manufacturing of machinery. Therefore, the growth of the manufacturing industry influences the growth PT Selula Dwiphaloka Teknologi. Report from Ministry of Industry of Indonesia (2018) indicates that the growth of Non-Oil and Gas Industry, Manufacturing Industry, and National Economic Growth together had slightly increase in 2017 and 2018 [3]. When growth is good and rising, of course, demand for services such as those provided by MSMEs will also increase. Conversely, if growth is declining, of course, the companies engaged in the industry will reduce costs or save costs and impact the sales of PT Selula Dwiphaloka Teknologi.

In B2B marketing, PT Selula Dwiphaloka Technologi is very dependent on personal selling. PT Selula Dwiphaloka Technologi usually sends e-mails and attach a company profiles booklet or give a direct presentations. However, according to the owner, the company profile that was sent was usually not so accepted and felt difficult to understand by the purchasing department of the consumer. They also already have a website, but it is not used optimally where the number of visitors per month is still below five people. On the Google search engine, the PT Selula Dwiphaloka 
Technologi site is also difficult to find when using search keywords. Consumer complaints also often occur. Consumer complaints occur due to consumer expectations of the machines design not in accordance with the results. Here it is found that in the presentation process in front of consumers, there is still a gap between consumers' understanding about the machine design. This problem occurred because of ineffective communication and lack of Standard Operating Procedure of the sales. Marketing team also sometimes skipped important step to make a deal with customer by not talk face to face to the user of the machine that will be created or not conducting field survey to gain more detailed information about the user expectation. The marketing team also does not have written guidelines for guidance and does not have detailed records or written data about consumers. Therefore, this paper was prepared to help improve personal sellin of the MSME by developing a personal selling SOP and also improving the website and company profile booklet of PT Selula Dwiphaloka Teknologi.

\section{LITERATURE REVIEW}

\section{A. B2B Marketing}

B2B (business to business) markets are markets for products and services, from local to international, purchased by a business company, government or other institution, for incorporate (for example ingredient ingredients or components), for consumption (for example process material, office supplies, or consultant services), for use (for example equipment installation), or for resale [4]. The purchasing process is more complex when compared to $\mathrm{B} 2 \mathrm{C}$, where the stages generally carried out by the organization on buying process are sequentially starting from problem recognition, general description of need, product specifications, search suppliers, acquisition and analysis of proposals, supplier selection, selection of order routines and performance review [4].

The purchase process also involves many parties which the parties can have their respective roles: the role of the user (the person who uses it), the gatekeepers (who control the information), influencers (which influence the purchasing decision), deciders (actually decide), and the buyer (who formally has the power to choose a supplier) [4].

Marketing communication is a tool used by companies to inform, persuade, and remind consumers - directly or indirectly - about products sold [5]. Companies can choose various types of communication facilities in the marketing communications mix such as using advertising, sales promotion, holding events, public relations, online media and social media, mobile marketing, direct marketing, and personal selling [5].

Decisions taken to choose marketing communication, need to pay attention to the target consumers. The content, structure, and style of the message that will be communicated and the way it is presented and the media channel that will be used are tailored to the target consumers so that they can reach the target consumers [6].

Due to the complexity of the B2B buying process involving many parties, the sales person plays an important role in maintaining contact with consumers through personal selling [7].

\section{B. Personal Selling}

Personal selling is a face-to-face interaction with one or more potential consumers who aim to make presentations, answer questions and get orders from consumers. Personal selling is the most effective communication tool for building relationships with buyers [5]. In the process of personal selling, a salesperson will face a variety of situations, but to carry out his duties, there are basic steps that must be achieved, starting from prospecting and qualifying, planning the sales call, approaching the prospect, making the sales presentation and demonstration, negotiating resistance, confirming and closing the sales, and finally follow up [8]. The salesperson can use marketing tools that are usually catalogs, brochures, company websites, presentations and so on. In making personal selling tools such as making brochures or company profiles during presentations, there are several criteria with technical details as follows: able to answer deep questions from experts owned by consumers, able to provide information for those who are not decision makers about the offer made, and able to build credibility with consumers [8].

Based on research by Murphy \& Sashi (2018), it is explained that personal communication has more interactive and positive results compared to digital communication. The more interactive things are related to dyatic contact (contact between buyers and suppliers), social interactions that occur, and reciprocal feedback. Personal communication which is carried out directly will have a higher value of participation and social value. But digital communication will be more interactive than personal communica- tion if it is concerned with the topic of sharing information related to tasks and satisfaction will also increase through digital roles [9].

\section{Standard Operating Procedure}

Standard Operating Procedures are a series of instructions that are carried out on an organization. The SOP is intended to maintain the quality of assurance of the activities carried out by an organization to remain consistent over time. If the organization does not have an SOP, then the organization does not function properly because it does not have a clear guideline flow [10].

SOPs have several important benefits, including clarifying the functions and roles of each position in the organization so that there is no misuse of work activities, clarifying the flow of tasks or activities carried out by each staff employee and avoiding failures or errors, doubts, and 
duplicating work activities in the organization. SOPs need to be developed and used because they are an integral part of a successful quality system. SOPs provide information to do work or tasks correctly, and facilitate consistency in the quality and integrity of the final results of work [11].

There are two factors that determine the form of SOP to be used, namely the number of decisions that will be taken and the number of steps to be taken in a process. SOP forms that can be used as follows [12]:

\section{1) Simple Steps}

This form is used for short routine procedures, not too much need for decisions and steps to be taken a little.

\section{2) Hierarchical Steps}

This form is in the form of an SOP that explains the stages that are more detailed and very consistent must be done compared to simple steps. There are large stages and details of each of these stages.

\section{3) Graphic Procedures}

This form is used for procedures that are quite long (more than 10 steps) but do not require many decisions. Graphics can help simplify a process from a long form to a short form.

\section{4) Flowchart}

Flowchart is a simple graph that explains the process steps in making a decision. The form of a flowchart is used for procedures that have many decisions and many steps to do. In making a flowchart form SOP, symbols are needed that can help explain each step of the process.

\section{Website}

Website is a part of digital marketing. Digital marketing is digital technology where it is able to create integrated communication, has a target, and is measurable, which will help companies to obtain and retain customers while building deeper relationships. Digital marketing has a number of goals called 5Ss of marketing [13]. The five goals / benefits of digital marketing or e-marketing are:

1. Sell- Grow Sales - to expand distribution channels for consumers who cannot be served offline.

2. Serve - Add Value - to provide added value to consumers or inform product development with online chat and feedback.

3. Speak - Get Closer to Customer - to create two-way communication by using websites, e-mail, and polls, also trying to talk to reach key influencers using e-PR.

4. Save - Save Cost - by using online communication such as e-mail, sales, and transaction services can reduce staff costs, printing, and shipping costs (via digital).

5. Sizzle - Extend the Brand Online - the company can provide new propositions and new experiences for customers.

A website is a place where a company can operate so that its consumers can gather information related to products or services provided by the company and have the potential to make purchases [14]. The website is also a form of online marketing, where if the design of the company's site is properly arranged, the company website will be easily found on search engines like Google and will be accessible to consumers who have potential purchases [14].

7C's framework is a framework that can be used by companies as a guide for designing customer interfaces (CIs) when creating a website where interfaces are on a website is a virtual representation of the value chosen by the company to be displayed to consumers. In $7 \mathrm{C}^{\prime} \mathrm{s}$ Framework there are two concepts that can help the development of the system on how to use all 7C's elements simultaneously, namely first is fit which is described by how much influence each element of $7 C^{\prime} S$ has on the business model, and the second is reinforcement based on the level of consistency of each element. The 7C's framework are context, content, community, customization, communication, connection and commerce [15]. The results from McLean's study (2017) shows that the quality of the information on the website as well as the credibility of the website has a significant effect on the success of the search. Customers should perceive the website as being credible and containing good quality information [16].

\section{E. Company Profile}

Company profile is one of the marketing communication facilities in the form of book-shaped media that is used to inform potential consumers about the company's products or services or other messages to be conveyed [5]. Company Profile is a marketing tool that can communicate the company's brand image by representing the general description of the company and services or products offered [17].

The function of the company profile is as the identity of the company, means of communication, and information media. Company profile usually covers the history of the company, philosophy and corporate culture, greetings from the owner of the company, vision and mission, company address, human resources, company achievements, and descriptions of the products and services offered [17].

In print media, visual appearance is the dominant and important thing in determining the effectiveness of message delivery. The visual display of print media must attract attention, be able to communicate writing, images, or ideas and work in synergy with the title so that the message to be conveyed can be effective [6].

\section{MethodOLOGY}

The research used business coaching method that involves a local company in the MSME scale, namely PT Selula Dwiphaloka Teknologi. They are a machine making contractor for B2B customer. Business coaching is a method to map the conditions and problems of MSMEs which are then followed up to implement solutions to selected problems and have an impact on improvement. Qualitaitve study was used to collect data by interviewing the director, managers and marketing staff of PT Selula Dwiphaloka Technology divided into 10 meetings until the 
implementation of solutions. The Qualitaitve study aims to observe, record, and describe the condition and problem of these MSMEs. The results of the interview are analyzed to find gaps by comparing ideal conditions and real conditions in MSMEs. Pareto analysis was used to determine what problems must be followed up first and have a major impact on MSMEs.

Quantitative methods were also used in this study in the form of surveys. The survey was conducted to support evidence of an increase between before and after the improvement of company profile and website. The variables used are visual, quality information and brand image, each of which has 3 questions as in Table 1. The questionnaire shows the company profile image and website both before and after improvement where the respondent answers the same questions both before and fter improvement to the company profile and website.

The sampling technique using judgmental sampling method, which is a nonprobability sampling technique where the respondent was chosen based on the assessment by the researcher and considered the respondent suitable to be a source of data. Respondents in this survey amounted to 79 people, using a Likert scale (1-6) from strongly disagree to strongly agree. The results of the collected data were analyzed descriptively with SPSS to compare means values from before and after improvements to the company profile and website.

TABLE 1.

VARIABLE SURVEY QUESTIONNAIRE

\begin{tabular}{lll}
\hline \multicolumn{1}{c}{ Variable } & \multicolumn{1}{c}{ Indicator } & Reference \\
\hline Visual & $\begin{array}{l}\text { Layout is very good } \\
\text { Very good graphics } \\
\text { The text is very good }\end{array}$ & \\
& Information easy to read & \\
Inform-ation & Information is easy to understand \\
Quality & Information provided is accurate & \\
& Looks credible & \\
Brand Image & Looks arranged professionally \\
& I have a good feeling towards (Company & \\
& Profile / Website)
\end{tabular}

\section{RESULTS AND DISCUSSION}

Based on the results of interviews and analysis, there were four problems faced by MSMEs PT Selula Dwiphaloka Technology, namely the need for SOP personal selling, company profile booklet improvements, website improvements, and HR management. The following is pareto analysis of the results of mapping the conditions and problems of MSMEs shown in Figure 1.

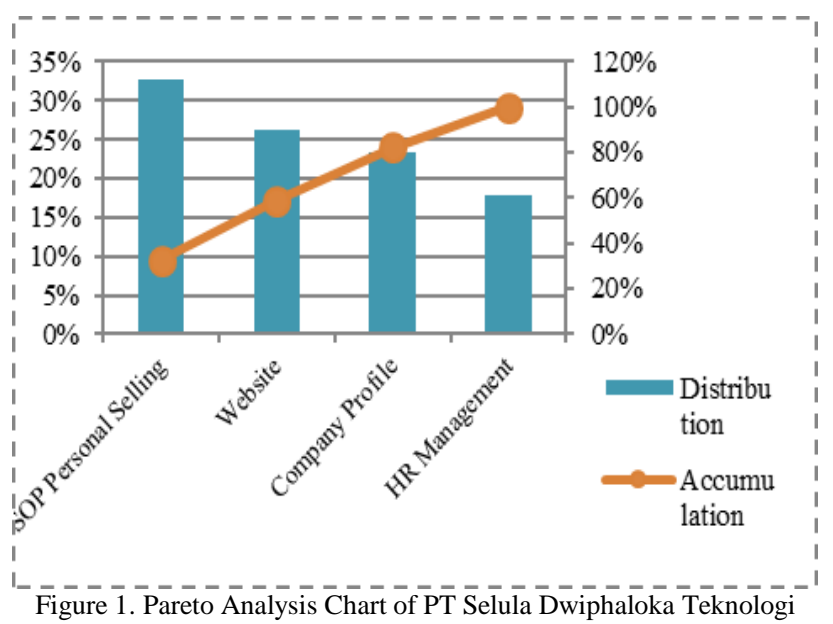

In Figure 1, the problem of PT Selula Dwiphaloka Teknologi shows that the biggest impact is the absence of SOP personal selling so that sales activities are not carried out consistently which also affects the complaints and sales of MSMEs themselves. Then the website and company profile that does not have an attractive design because the owner does not have the expertise to make a design. And there are HR management problems such as there is no an employee development plan and need to recruit new staf of marketing division. This was found from the results of interviews and observations, along with quotes from interviews with MSME owners.

" Every beginning of the month, we only see a few lists of our customers who have a high frequency ordering our products, then we contact them, ... We don't have marketing reports but we have a list of customers, our new customers mostly come from referrals and rarely find new one by our marketing division, ....

Sometimes we also have to face complaints that the root of the problem is that people who have a big influence on the buying process don't meet us at the initial bidding stage...

the purchasing department sometimes looks at our web or company profiles, isn't too interested and I think they don't understand what we're selling. "

Based on the results of the Pareto analysis, three main problems will be discussed in the implementation of the proposed research improvement with this business coaching method, namely developing Personal Selling Standard Operating Procedure (SOP), improving MSMEs website and improving company profile booklet because it gives a significant impact on changes at PT Selula Dwiphaloka Teknologi. 


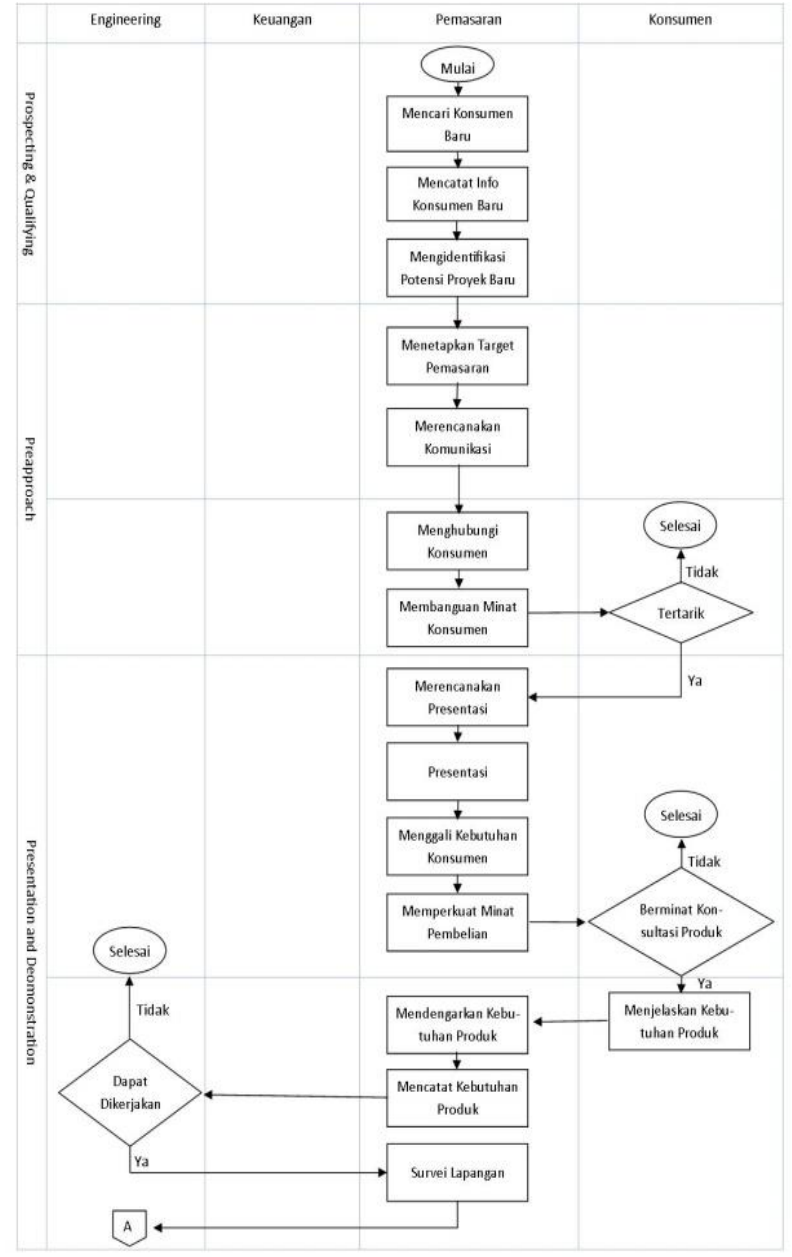

Figure 2. Personal Selling SOP Flowchart of PT Selula Dwiphaloka Technologi

PT Selula Dwiphaloka Technologi is a company engaged in manufacturing machinery for industry, therefore personal selling is the main marketing communication used by these MSMEs. In the initial stages of preparation, by discussing with the owner regarding the process that is usually done by the MSME. Then evaluating the process to be developed or improved, and compiling a general description of the draft SOP that will be created. SOPs are arranged so that MSMEs have written and structured guidelines.

In theory, the personal selling process consists of seven steps which are then adapted to adapt to the business processes of MSMEs. The process start with to get the target number of the consumer, send e-mail or whatsapp messages, presentations to prospective customers, listen to prospective consumer problems, conduct field surveys, solution presentations, negotiation, closing, follow-up to delivery of goods and the last is maintaining the relationship with the consumer.

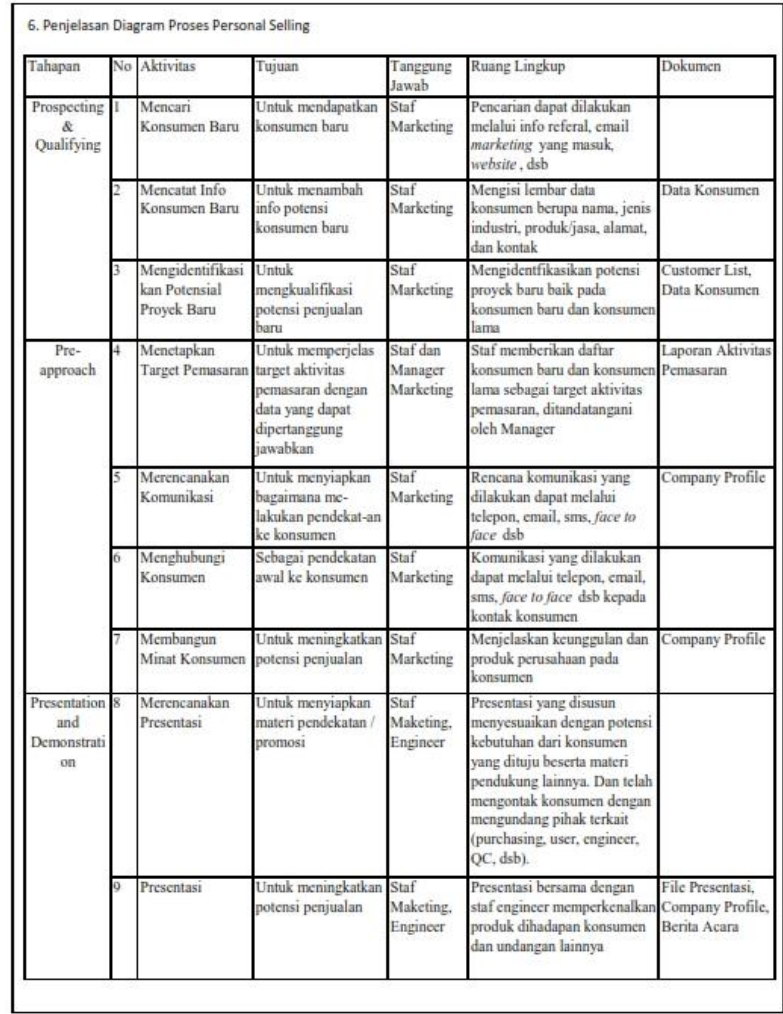

Figure 3. Personal Selling SOP Table of PT Selula Dwiphaloka Technologi

Then to prepare the SOP, the theoretical reference is used and adjusted to the marketing process carried out by PT Selula Dwiphaloka Teknologi. The SOP made consists of several parts as follows:

1. The first part is the introduction to the company's vision and mission, the purpose of the SOP, and the scope of the SOP. Here it is written to explain the purpose of the SOPs compiled and what things are covered in the SOPs prepared.

2. The second part is a flowchart or diagram that describes the overall personal selling activity.

3. The third part is a detailed explanation of each activity in the form of a table. The objectives, responsibilities, scope and documents needed at each stage are written on the table.

4. The fourth part is in the form of examples of supporting documents in personal selling activities. Documents included in the SOP personal selling PT Selula Dwiphaloka Technologi, namely, consumer data documents, consumer lists, sales activity reports, and sales reports.

The following is shown in Figure 2 in the form of the initial flowchart and Figure 3 the table that consist explanation of steps in the flowchart from SOP personal selling PT Selula Dwiphaloka Teknologi:

The company profile is often used by MSME of PT Selula Dwiphaloka Technologi to introduce the company and products offered, and Figure 4 is an old version 
The $1^{\text {st }}$ International Conference on Business and Management of Technology (IConBMT)

August 3rd 2019, Institut Teknologi Sepuluh Nopember, Surabaya, Indonesia

of the MSME's company profile start page. Company profile is a marketing tool that can communicate brand image of company with a general overview of the company and what products are offered. Company profile usually covers about the history of the company, philosophy and corporate culture, greeting of the owner of the company, its vision and mission, the address of the company, human resources, achievements of the company, and descriptions of the products offered. With such a company profile function, it is important for PT Selula Dwiphaloka Technologi to have an adequate company profile.

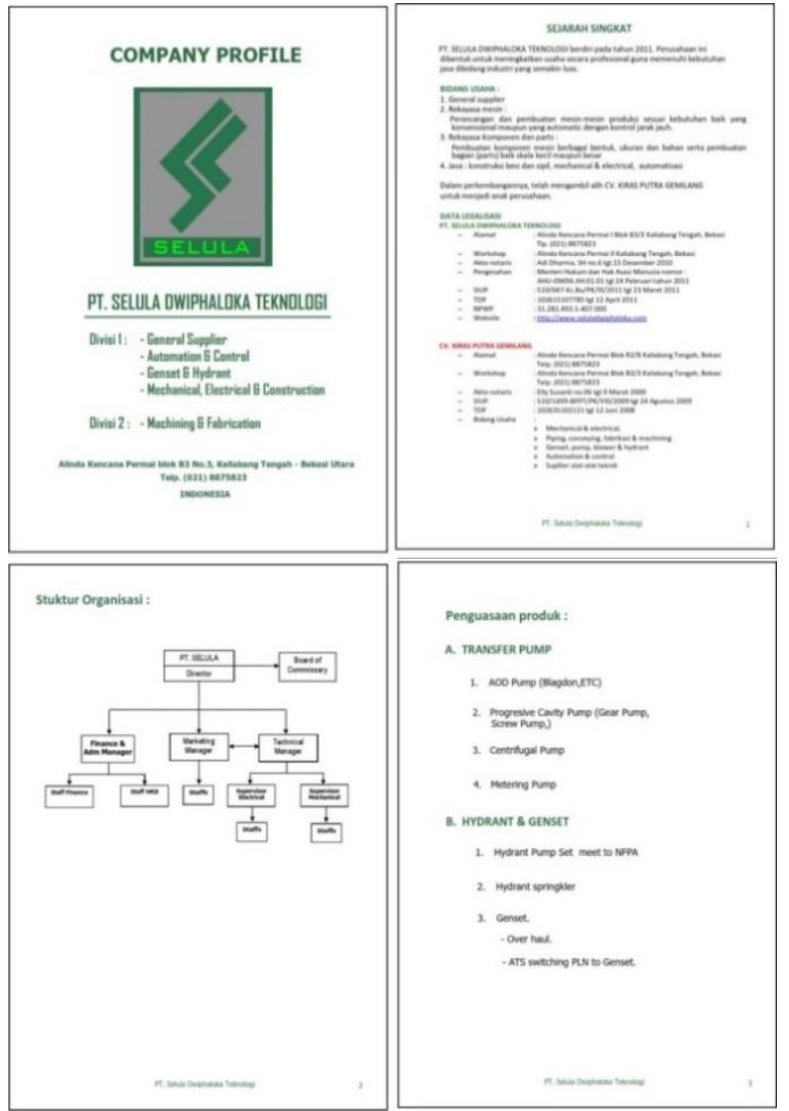

Figure 4. Old Company Profile of PT Selula Dwiphaloka Teknologi

From the results of discussions with the owner, the improvements made first are determined that there are three major parts of the company profile content, namely the corporate identity section; products offered and project experience; and legal data and company contacts. Next is the design of the company profile, from the results of the discussion, the green color as found on the company logo will still be maintained in the new company profile. Additions made to the new design are the use of blue which symbolizes professionalism and feels it matches the values of the company. Then to make the new company profile design looked more professional, presentable and attractive, some changes is done by improving the layout, images and text. In Figure 5 is shown some pages of the new company profile design of the MSME.

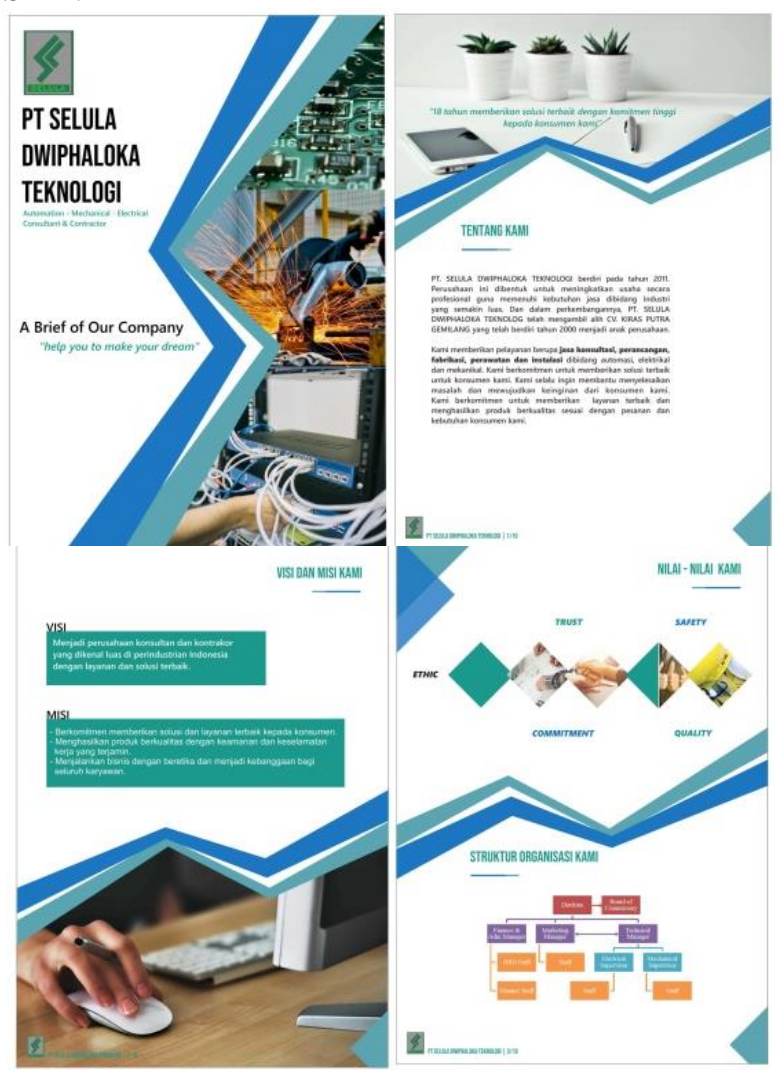

Figure 5. New Profile Company of PT Selula Dwiphaloka Teknologi

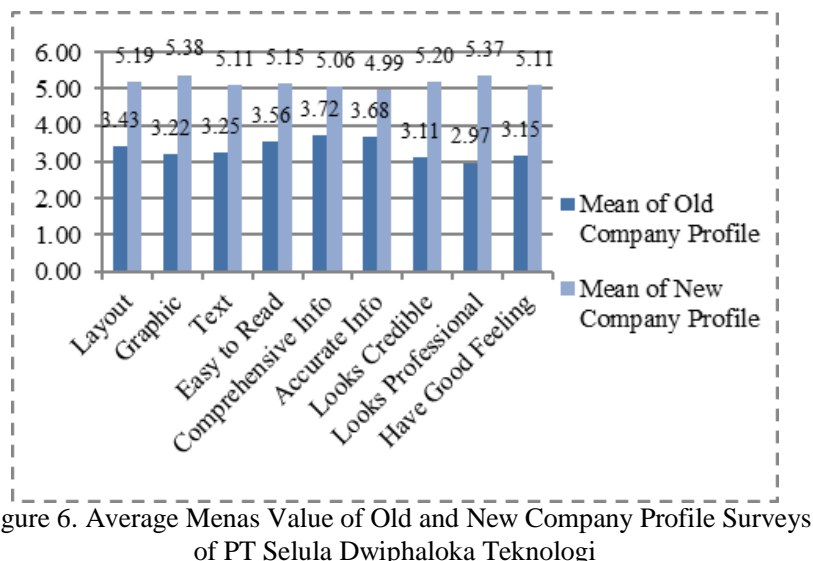

Based on the survey results, there is an increase in the visual aspects, the quality of information and credible imagery from the new company profile. The new mean value becomes 5.17 or the respondent agrees with the visual aspects, the quality of information, and the credible image that is good compared to the old company profile with the mean of 3.34. The average value of each indicator can be seen in Figure 6. This significant change requires some improvement that make the company profile looked more attractive. The improvement is done by make some changes such as changes in layout, images, and text, then the quality 
of information that is easier to read, easy to understand and accurate. By doing this, from the survey is can be conclude that the respondents considered the new company profile is looked more credible, professional, and respondents had a better feeling than the old one.

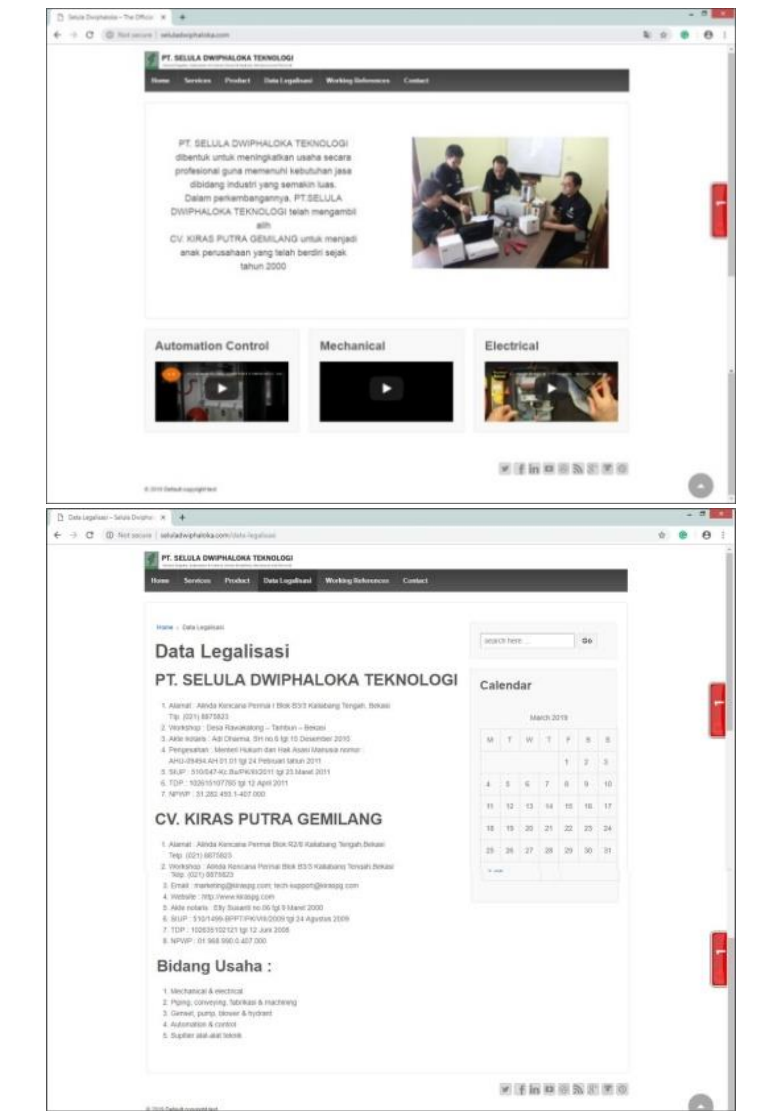

Figure 7. Display of Old Website of PT Selula Dwiphaloka Teknologi

Website is a place where a company can use as communication channel so that its consumers can gather information related to products provided by the company and have the potential to make purchases. PT Selula Dwiphaloka Technologi has long had the company's official website, but the site has not provided more benefits to the company. The old display of the old website can be seen at the Figure 7. Then to make the new design of MSMEs websites is done by using 7C's framework. The first component of 7C's framework is content. Context of the website PT Selula Dwiphaloka Technologi focuses on the context which has a dominant aesthetic and functional because the company want to explain all the service and product that offered and attract the consumer with professionally look design. Then in terms of content, the website has the dominant content containing information on the products offered. In terms of community is a nonexistent community because it only contains information about the company. In terms of customization, it is included in the generic. The communication aspects is using a broadcast communication method. In terms of connection, is categorized as a destination for it is not linking to other sites. In terms of commerce, website of PT Selula Dwiphaloka Technologi is categorized as low because there are no transactions that take place through the website.

Based on the framework, the major changes made are on the homepage of the MSME's website. The homepage of the site is designed to be more information-rich, so that without the need to open another page, a brief explanation on the initial page has helped. Site design is made in line with the company profile design, especially the color elements used, namely green and blue to strengthen the image of MSME. In Figure 7 is the initial view when the visitor first enters into the site were greeted with the images and the initial opening remarks to introduce PT Selula Dwiphaloka Technologi as a manufacturer of specialized custom design products. If the visitor looks down or scroll will find a brief description of the company and company values. Furthermore, if visitors continue to look down the page or scroll, they will find service information and expertise from the company. And there are several client company logos. Then at the very bottom of the homepage, the visitors can find information about the address and company contacts.

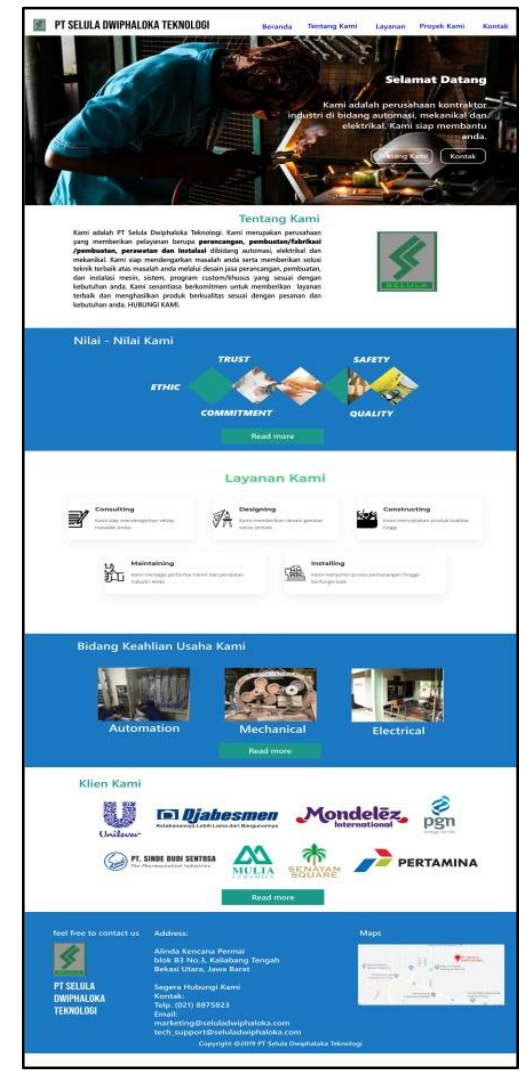

Figure 7. Display of New Website of PT Selula Dwiphaloka Teknologi

Based on the results of the survey also seen an increase in the average visual aspects, quality of information, and credible images from old websites and new 
websites. Respondents agreed that the new website is better than the old website with the average value of the indicator is 5.31 compared to 3.15 . The average detail value of each indicator can be seen in Figure 8. This significant change requires some improvement that make the website looked more attractive. The improvement is done by make some changes such as changes in layout, images, and text, then the quality of information that is easier to read, easy to understand and accurate. By doing this, from the survey is can be conclude that the respondents considered the new website is looked more credible, professional, and respondents had a better feeling than the old one.

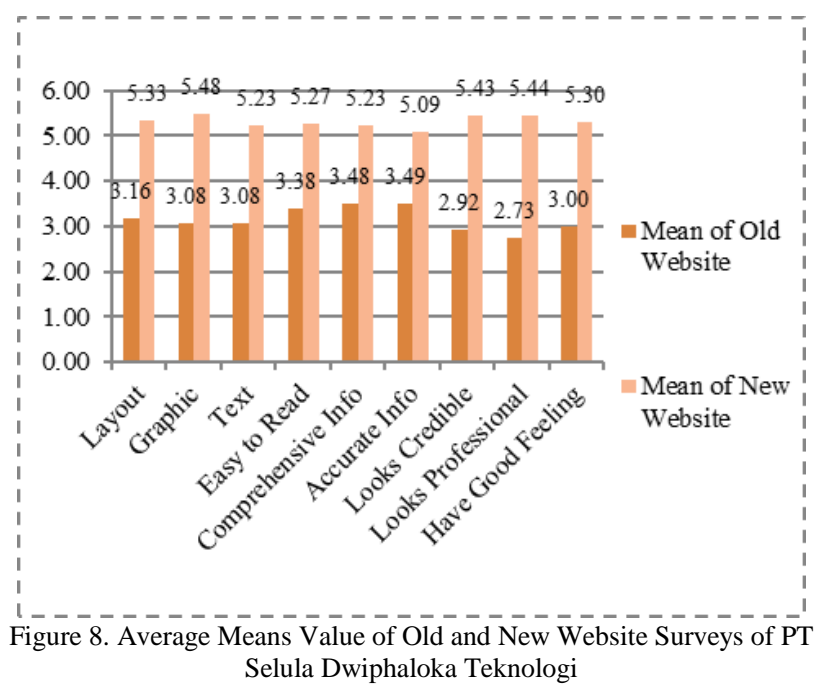

\section{CONCLUSION}

From the results of the study, it was concluded that in order to develop a personal selling SOP, the theory used could be adapted to the MSME business process. The form of SOP used can be a process flow diagram to facilitate understanding for users. This SOP can help MSMEs PT Selula Dwiphaloka Teknologi to run consistently personal selling activity. However, this SOP is still in the initial development stage, so that in the future MSMEs must also conduct evaluations and make changes to better SOPs.

Improvements to layouts, images, and texts as well as improving the quality of information so that it is easier to read, understand, and provide accurate information on company profiles and websites can improve the assessment of the visual aspects and quality of information. Visual improvements and information quality also increase the brand image of MSMEs when seeing company profile and new website because it looks more credible, professional compared to the old one.

However, further development also needs to be done, such as constantly updating the content contained in the company profile and website which is also balanced with the quality of the product, according to what is offered at company profile and website, so that the brand image of MSMEs is getting better and expected to influence sales. Utilizing Google advertising services can also be further developed by MSMEs to advertise the website to help marketing activities of PT Selula Dwiphaloka Teknologi.

\section{REFERENCES}

[1] G. G. Quddus, "Pemangkasan Tarif PPh UKM Difinalisasi," Kontan.co.id, Jakarta, 11-Apr-2018.

[2] A. Gilmore, "Entrepreneurial and SME marketing," J. Res. Mark. Entrep., vol. 13, no. 2, pp. 137-145, Oct. 2011.

[3] Kementrian Perindustrian RI, "Analisis Perkembangan Industri Edisi 1 2019," 2019.

[4] M. D. Hutt and T. W. Speh, Business Marketing Management $B 2 B, 10$ th ed. Canada: South-Western/Cengage Learning, 2010.

[5] P. Kotler and K. L. Keller, Marketing Management, 15th ed. Boston: Pearson, 2016.

[6] G. E. Belch and M. A. Belch, Advertising and Promotion: An Intregrated Marketing Communications Perspective, 10th ed. USA: McGraw-Hill Education, 2015.

[7] W.-L. Wang, E. C. Malthouse, B. Calder, and E. Uzunoglu, "B2B content marketing for professional services: In-person versus digital contacts," Ind. Mark. Manag., vol. 81, pp. 160168, Aug. 2019.

[8] R. E. Anderson, "Personal selling and sales management in the new millennium," J. Pers. Sell. Sales Manag., vol. 16, no. 4, pp. 17-32, Jan. 1996

[9] M. Murphy and C. M. Sashi, "Communication, interactivity, and satisfaction in B2B relationships," Ind. Mark. Manag., vol. 68, pp. 1-12, Jan. 2018.

[10] The U.S. Environmental Protection Agency (EPA), Guidance for Preparing Standard Operating Procedures (SOPs). Washington DC: The U.S. Environmental Protection Agency (EPA), 2007.

[11] A. Herdiyanti, A. C. Puspitaningrum, H. M. Astuti, and U. L. Yuhana, "Pembuatan standard operating procedure pengembangan sistem informasi manajemen: studi kasus DPTSI ITS," SISFO, vol. 08, no. 01, pp. 67-68, Sep. 2018.

[12] R. Stup, "Standard Operating Procedures: A Writing Guide," PennState Extension, 2012. [Online]. Available: https://extension.psu.edu/standard-operating-procedures-awriting-guide.

[13] D. Chaffey and P. R. Smith, Emarketing Excellence: Planning and Optimizing Your Digital Marketing, 4th ed. New York: Routledge, 2012.

[14] S. McPheat, Developing Internet Marketing Strategy. USA: Ventus Publishing, 2011.

[15] J. F. Rayport and B. J. Jaworski, Introduction to E-commerce. Boston: McGraw-Hill, 2001.

[16] G. J. McLean, "Investigating the online customer experience - a B2B perspective," Mark. Intell. Plan., vol. 35, no. 5, pp. 657672, Aug. 2017.

[17] R. Kriyantono, Public Relations Writing: Media Public Relations, Membangun Citra Korporat. Jakarta: Kencana Prenada Media Group, 2008.

[18] S. Cebi, "Determining importance degrees of website design parameters based on interactions and types of websites," Decis. Support Syst., vol. 54, no. 2, pp. 1030-1043, Jan. 2013. 